\title{
Activities of Carbon and Nitrogen Metabolism Enzymes during Germinating Sorghum Seeds and Early Seedlings Growth
}

\author{
R. Ben Mrid ${ }^{1}$, R. El OMari ${ }^{1}$, Y. Bouargalne ${ }^{1}$, N. El Mourabit ${ }^{2}$ and M. Nhiri ${ }^{1 *}$ \\ ${ }^{1}$ Laboratoire de Biochimie et Génétique Moléculaire, Faculté des Sciences et Techniques de Tanger, \\ BP 416, 90000 Tanger, Morocco \\ ${ }^{2}$ Centre Régional de la Recherche Agronomique de Tanger, 78 Avenue Sidi Mohamed Ben Abdellah, \\ Tanger 90010, Morocco
}

(Received 2 November 2016; Accepted 24 April 2017;

Communicated by A. Pécsváradi)

\begin{abstract}
Carbon and nitrogen metabolism are regulated by complex mechanisms in order to optimize growth and development of plants and play a major role during germination and postgerminative growth. The objective of the current work was to establish the degree of changes in activities of key enzymes implicated in these two metabolism pathways during germination and post-germinative growth such as; glutamine synthetase, glutamate dehydrogenase, phosphoenolpyruvate carboxylase, malate dehydrogenase, isocitrate dehydrogenase and aspartate aminotransferase. We have observed that during germination and seedlings development the most activities of nitrogen and carbon metabolism enzymes were correlated (nearly show similar kinetic changes) and influenced by their cellular environment and developmental stage. Therefore, higher activities of these enzymes were observed in the seed, root and shoot at early stages of the post-germinative phase could be effectively linked to the demand of de novo proteins to ensure a good development of seedlings.
\end{abstract}

Keywords: carbon and nitrogen metabolism, enzyme activity, germination, post-germinative stage, Sorghum bicolor

Abbreviations: AAT: aspartate aminotransferase; BSA: bovine serum albumin; DAI: days after imbibition; EDTA: ethylenediaminetetraacetic acid; GDH: glutamate dehydrogenase; GOGAT: glutamate synthase; GS: glutamine synthetase; ICDH: isocitrate dehydrogenase; MDH: malate dehydrogenase; OAA: oxaloacetate; PEP: phosphoenolpyruvate; PEPC: phosphoenolpyruvate carboxylase; PMSF: phenylmethylsulphonyl fluoride; PVP: polyvinylpyrrolidone; TCA: tricarboxylic acid.

\section{Introduction}

Germination and seedlings development implies different physiological and biochemical processes. Carbon and nitrogen metabolisms are the main pathways besides acting of several hormones controlling these processes. In fact, these two metabolism pathways are regulated by complex mechanisms in order to optimize growth and development of plants and play a major role during germination and post-germinative growth (Osuna et al. 2015). 
It is now well known that de novo protein synthesis is required for germination. Amino acids are present in their free form in non-germinated seeds. However, the most part of these amino acids are derived from storage protein degradation during germination (Oaks 1997). The amino acids are released from proteins reserves and represent the source of ammonium that will be re-assimilated to synthesize de novo amino acids (Guan et al. 2015).

Ammonium is directly assimilated into amino acids via glutamine synthetase (GS) and glutamate synthase (GOGAT) (Valadier et al. 2008). Nitrogen initially stored in glutamine is transferred to a carbon skeleton (2-oxoglutarate) to produce two molecules of glutamate (Hodges et al. 2003). Nevertheless, when ammonium is present in greatest quantity, other metabolic pathways could carry out the ammonium assimilation. Under these conditions, glutamate dehydrogenase (GDH), that catalyses the reversible deamination of glutamate to 2-oxoglutarate, has been proposed to play a role in ammonium assimilation (Setién et al. 2013). Nitrogen incorporated into glutamine and glutamate can be redistributed to other amino acids, mainly by the action of transaminase or aminotransferase as aspartate aminotransferase (AAT) which catalyzes the reversible transfer of an amino group from glutamate to oxaloacetate (OAA) to form aspartate and 2-oxoglutarate.

Phosphoenolpyruvate carboxylase (PEPC) is a cytosolic enzyme that is widely presented in bacteria, cyanobacteria, green algae, and in higher plants (Izui et al. 2004). PEPC catalyzes the irreversible $\beta$-carboxylation of PEP in the presence of $\mathrm{HCO}_{3}^{-}$to yield OAA. The OAA is then reduced by NAD-dependent malate dehydrogenase (NAD-MDH) to L-malate in the TCA cycle (Buchanan et al. 2000). The malate generated is converted to citrate which would leave the TCA cycle to be exported from the mitochondria to the cytosol via a citrate transporter (Hodges et al. 2003). At this point, the $\mathrm{NADP}^{+}$-isocitrate dehydrogenase (ICDH) may operate to produce the 2-oxoglutarate as proposed by Chen and Gadal (1990). The carbon generated by the action of PEPC, MDH and ICDH may be used by the nitrogen assimilation machinery to produce amino acids.

Sorghum is an important cereal in developing countries and was ranked the most important crop worldwide in terms of harvested area. It is the dietary staple for more than 500 million people in many countries and more than $50 \%$ of the global harvest takes place in Africa (El Omari et al. 2010). Sorghum is also a well-established model for molecular and physiological studies in photosynthesis and carbon metabolism (Nhiri et al. 1998). However, studies dealing on the interaction between carbon and nitrogen metabolism during germination and seedlings development of sorghum are poorly-known. Thus, the objective of the present study was to understand the contribution of key enzymes implicated in nitrogen and carbon metabolism during germination and post-germinative growth such as; GS, GDH, PEPC, MDH, ICDH and AAT.

\section{Materials and Methods}

\section{Plant material and growth}

Sorghum bicolor L. seeds were surface-sterilized with 5\% hypochlorite, and then washed thoroughly with distilled water to get rid of the bleach that can act negatively on germination. Seeds were germinated in Petri dishes containing sterile paper filter moistened with 
sterile distilled water and sealed with Parafilm. The plates were placed in the dark at $26^{\circ} \mathrm{C}$ temperature. Forty-eight $\mathrm{h}$ later, the plates were placed in a growth chamber. The environmental conditions in the growth chamber were 16 hours day $\left(28^{\circ} \mathrm{C}\right) / 8$ hours night $\left(22^{\circ} \mathrm{C}\right.$ ). Dry seeds (only for 0 day), imbibed seeds, shoots and roots were taken after 3,6 , $8,10,12$ and 15 days after imbibition (DAI) and immediately stored at $-80^{\circ} \mathrm{C}$.

\section{Enzymatic measurements}

Extraction and assay of GS, GDH, NADH-MDH and AAT

A $0.4 \mathrm{~g}$ of samples (dry seeds, imbibed seeds, shoots and roots) were extracted in 4 volumes of a $50 \mathrm{mM}$ Tris- $\mathrm{HCl}$ buffer ( $\mathrm{pH}$ 8) containing $14 \mathrm{mM} \beta$-mercaptoethanol, $1.4 \mathrm{mM}$ glycerol, $9.4 \mu \mathrm{M}$ leupeptin, $16.5 \mu \mathrm{M}$ chymostatin, $10 \mathrm{mM}$ glutamate, $1 \mathrm{mM}$ EDTA and $0.5 \mathrm{mM} \mathrm{MgSO}_{4}$. The homogenate was centrifuged at $20,000 \mathrm{~g}$ for $30 \mathrm{~min}$ at $4{ }^{\circ} \mathrm{C}$ to obtain a clarified supernatant. GS activity was measured using the transferase assay as described by Shapiro and Stadtman (1970). The GDH activity was carried out in the aminating direction as described by Sarasketa et al. (2014). NADH-MDH activity was assayed as described in Setién et al. (2014). AAT activity was measured by the method described by Rej (1979) with some modifications. The assay mixture contained: Tris-HCl $50 \mathrm{mM}, \mathrm{pH}$ 7.8, L-aspartate $50 \mathrm{mM}$, 2-oxoglutarate $10 \mathrm{mM}$, NADH $0.1 \mathrm{mM}, 2 \mathrm{U}$ of $\mathrm{MDH}$ and $20 \mu \mathrm{l}$ of extract. The reaction was initiated by adding 2-oxoglutarate.

\section{Extraction and assay of PEPC and $\mathrm{NADP}^{+}-\mathrm{ICDH}$}

A $0.4 \mathrm{~g}$ of samples (dry seeds, imbibed seeds, shoots and roots) were extracted in 4 volumes of a $100 \mathrm{mM}$ Tris-HCl, pH 8, buffer containing $10 \mathrm{mM} \mathrm{MgCl}_{2}, 1.4 \mathrm{mM}$ glycerol, 14 mM $\beta$-mercaptoethanol, 1 mM PMSF, 1 mM EDTA, 1 mM EGTA, $9.4 \mu \mathrm{M}$ leupeptin and $16.5 \mu \mathrm{M}$ chymostatin. The homogenates were centrifuged at $12,000 \mathrm{~g}$ for $15 \mathrm{~min}$ at $4{ }^{\circ} \mathrm{C}$. Supernatant was then saturated $(60 \%)$ with solid ammonium sulfate for 30 minutes. The saturated supernatant was centrifuged again in the same conditions and the resulting pellet was resuspended in the extraction buffer and used for enzyme assays. The PEPC activity was measured as described by Bakrim et al. (1993). The NADP ${ }^{+}-\mathrm{ICDH}_{\text {activity was }}$ measured according to Magalhaes and Huber (1991) with some modifications. The assay mixture containing: $50 \mathrm{mM}$ potassium phosphate buffer $(\mathrm{pH} 7.5), 1 \mathrm{mM} \mathrm{MnCl}, 1 \mathrm{mM}$ $\mathrm{NADP}^{+}$and $4 \mathrm{mM}$ isocitrate.

\section{Estimation of protein}

Protein was estimated by the method of Bradford (1976) using BSA as standard.

\section{Statistical analysis}

Data are the mean of six biological replicates \pm SD. Results were subjected to a one-way analysis of variance (ANOVA) using PASW statistics (version 18). Different letters indicate significant differences between the data of the stages (days) at $5 \%$ level. 


\section{Results}

Activity of GS and GDH in the seeds, shoots and roots at different development stages

In our results, enzymes involved in nitrogen metabolism (GS and GDH) increased drastically in germinating seeds. It were enhanced from $0.5 \mu \mathrm{mol} \mathrm{min}^{-1} \mathrm{~g}^{-1} \mathrm{FW}$ and $0.03 \mu \mathrm{mol}$

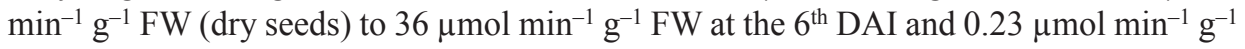
FW at the $8^{\text {th }}$ DAI for GS and GDH, respectively (Fig. 1A, D). GS and GDH activities decreased afterward to reach their lowest values after $15 \mathrm{DAI}\left(0 \mu \mathrm{mol} \mathrm{min}{ }^{-1} \mathrm{~g}^{-1} \mathrm{FW}\right.$ for

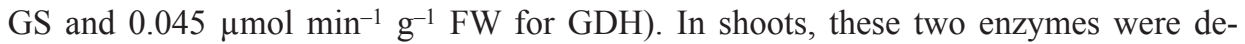

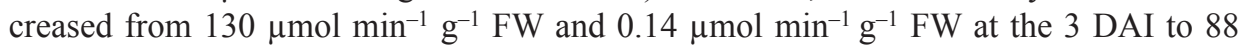

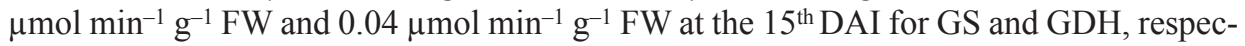
tively, and remain constantly low afterward (Fig. 1B, E). GS and GDH activities in roots showed a different profile. In fact, while GS activity present a general decrease (Fig. 1C), the GDH activity decrease from $0.178 \mu \mathrm{mol} \mathrm{min} \mathrm{m}^{-1} \mathrm{~g}^{-1} \mathrm{FW}$ at the $3^{\text {rd }} \mathrm{DAI}$ to $0.11 \mu \mathrm{mol}$ $\min ^{-1} \mathrm{~g}^{-1} \mathrm{FW}$ at the $6^{\text {th }} \mathrm{DAI}$ after remains stable from the $6^{\text {th }}$ to the $10^{\text {th }}$ and then increased again to $0.22 \mu \mathrm{mol} \mathrm{m^{-1 }} \mathrm{g}^{-1} \mathrm{FW}$ at the $12^{\text {th }} \mathrm{DAI}$ (Fig. 1F).

\section{Activity of PEPC and MDH in seeds, shoots and roots of sorghum at different development stages}

In seeds, the PEPC activity increased drastically from $0.08 \mu \mathrm{mol} \mathrm{min}{ }^{-1} \mathrm{~g}^{-1} \mathrm{FW}$ at $0 \mathrm{DAI}$ (dry seeds) to $0.72 \mu \mathrm{mol} \mathrm{min}^{-1} \mathrm{~g}^{-1} \mathrm{FW}$ at the $8^{\text {th }}$ DAI (Fig. 2A), and decreased from the $8^{\text {th }}$ to the $15^{\text {th }}$ DAI. In roots, this activity remains stable from the $3^{\text {rd }}$ to the $6^{\text {th }}$ DAI

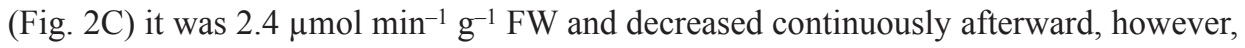

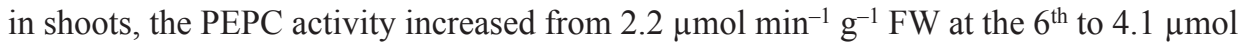
$\mathrm{min}^{-1} \mathrm{~g}^{-1} \mathrm{FW}$ at the $12^{\text {th }} \mathrm{DAI}$ and decreased afterward (Fig. 2B). The MDH activity in

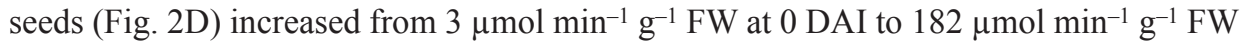
at the $8^{\text {th }}$ DAI and decreased until $15^{\text {th }}$ DAI. In roots and shoots, the MDH activity was decreased continuously from the $3^{\text {rd }}$ to the $15^{\text {th }}$ DAI (Fig. 2E, F).

Activity of ICDH and AAT in seeds, shoots and roots of sorghum at different development stages

In this study, the ICDH and AAT activities in seeds, increased from $0.02 \mu \mathrm{mol} \mathrm{min} \mathrm{m}^{-1} \mathrm{~g}^{-1}$ FW and $0.018 \mu \mathrm{mol} \mathrm{min}{ }^{-1} \mathrm{~g}^{-1} \mathrm{FW}$ (dry seeds) to $0.78 \mu \mathrm{mol} \mathrm{min}^{-1} \mathrm{~g}^{-1} \mathrm{FW}$ at the $8^{\text {th }} \mathrm{DAI}$ and $10.7 \mu \mathrm{mol} \mathrm{min}{ }^{-1} \mathrm{~g}^{-1} \mathrm{FW}$ at the $6^{\text {th }} \mathrm{DAI}$ for ICDH and AAT activities, respectively, and decreased afterward (Fig. 3A, D). In roots, these activities decreased continuously from the $3^{\text {rd }}$ to the $15^{\text {th }}$ DAI (Fig. 3C, F). A decrease in ICDH activity was also observed in seedling shoots (Fig. 3B); however, the AAT activity in shoots increased from $3.2 \mu \mathrm{mol}$ $\mathrm{min}^{-1} \mathrm{~g}^{-1} \mathrm{FW}$ at the $6^{\text {th }} \mathrm{DAI}$ to $5.1 \mu \mathrm{mol} \mathrm{min}^{-1} \mathrm{~g}^{-1} \mathrm{FW}$ at the $8^{\text {th }} \mathrm{DAI}$ and remained constant afterward (Fig. 3E). 

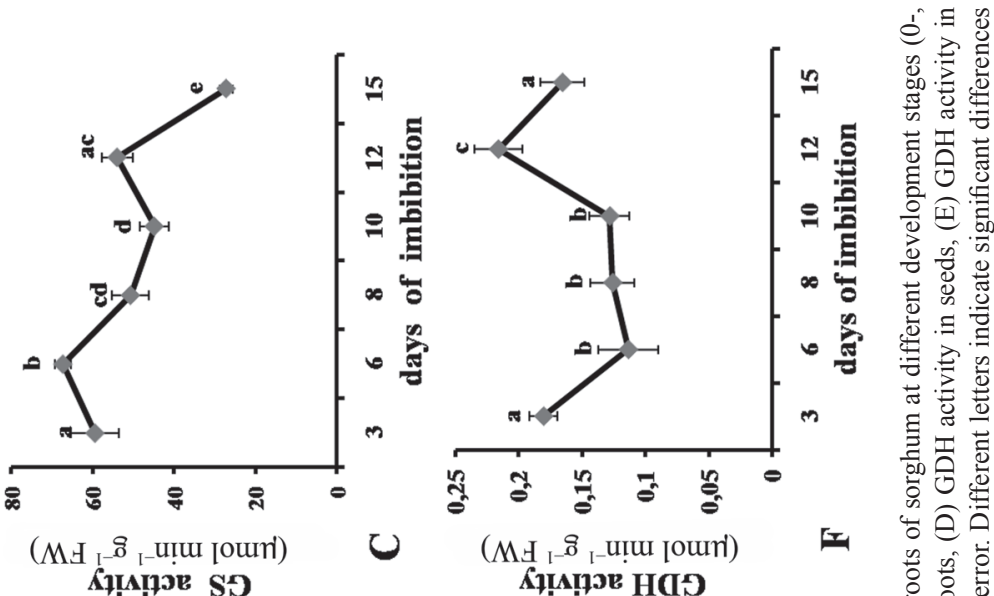

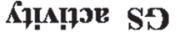

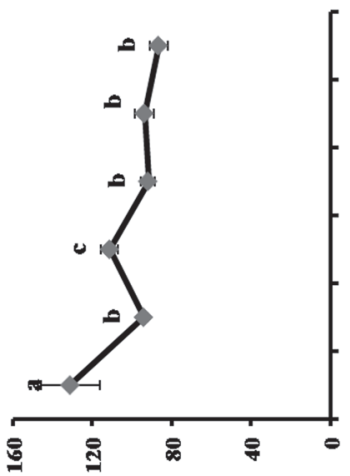

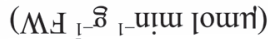

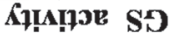

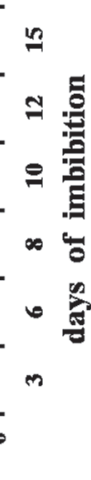

$\oplus$

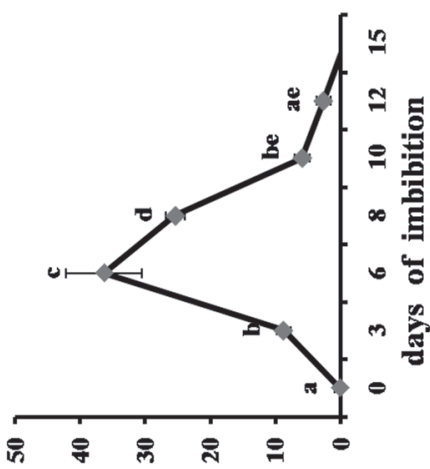

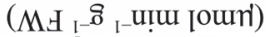

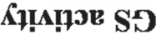

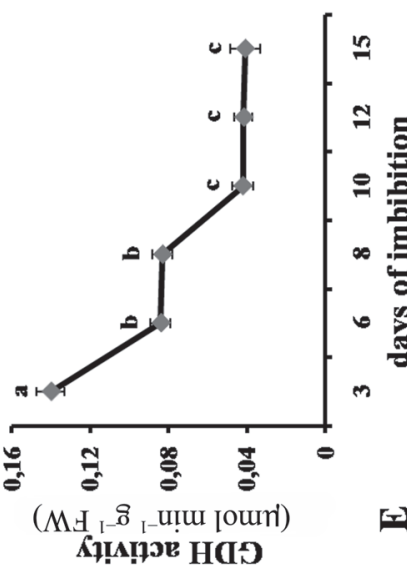

다

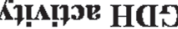

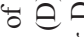

융

클

示焉

苍志坖

웡 웅

क o

苛䒕

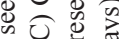

$\Xi \mathcal{0}$

(1)

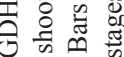

$\exists \dot{0} 0$

0.

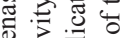

잉 己

突芯苛

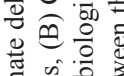

预

of

고

กิ

万人

凹

I

政

需

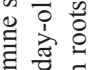

豞它.

志吉.

능 츨

空寽

安

- 1 近

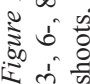



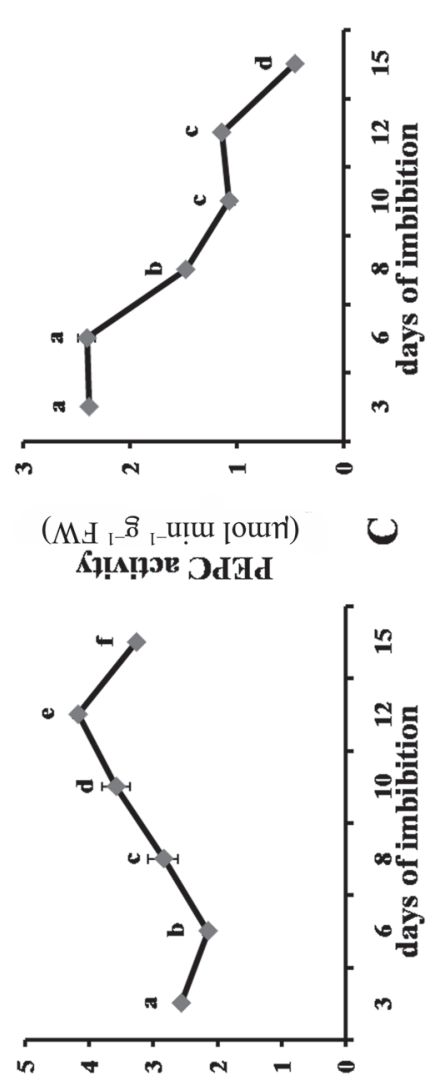

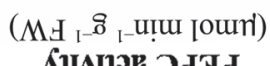

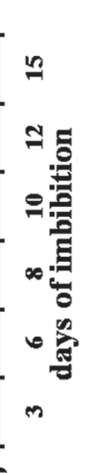

$\infty$
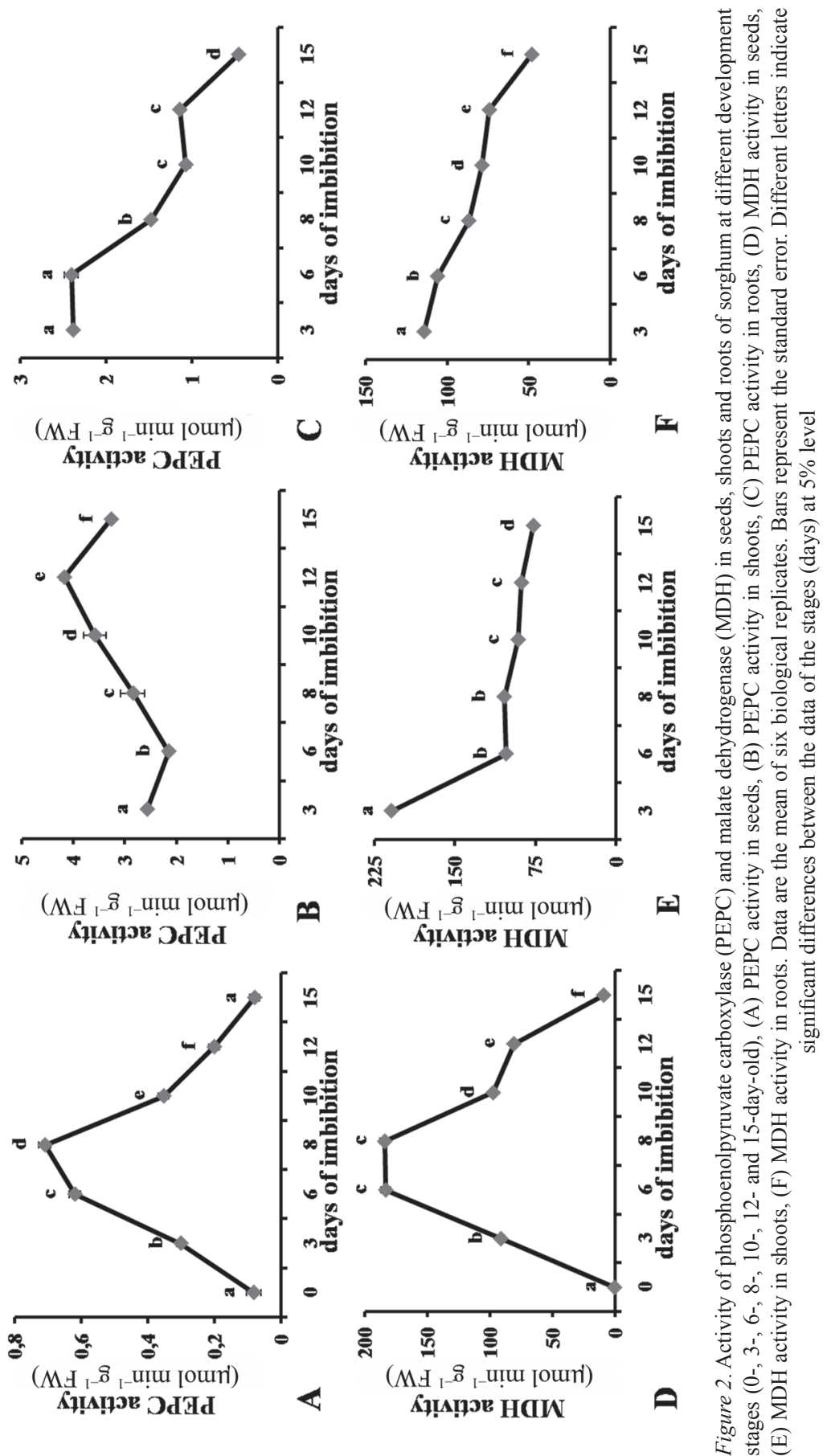

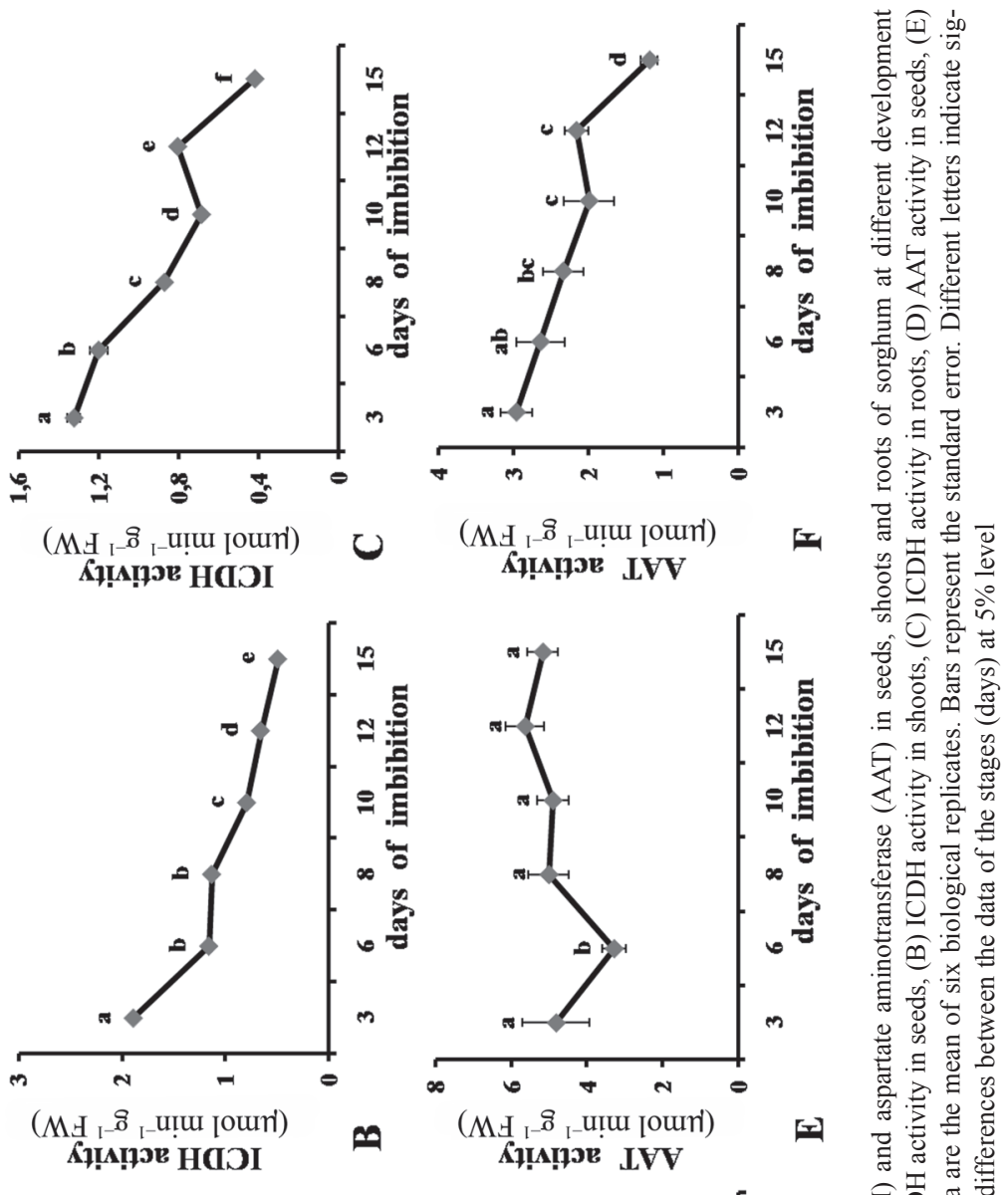

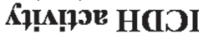
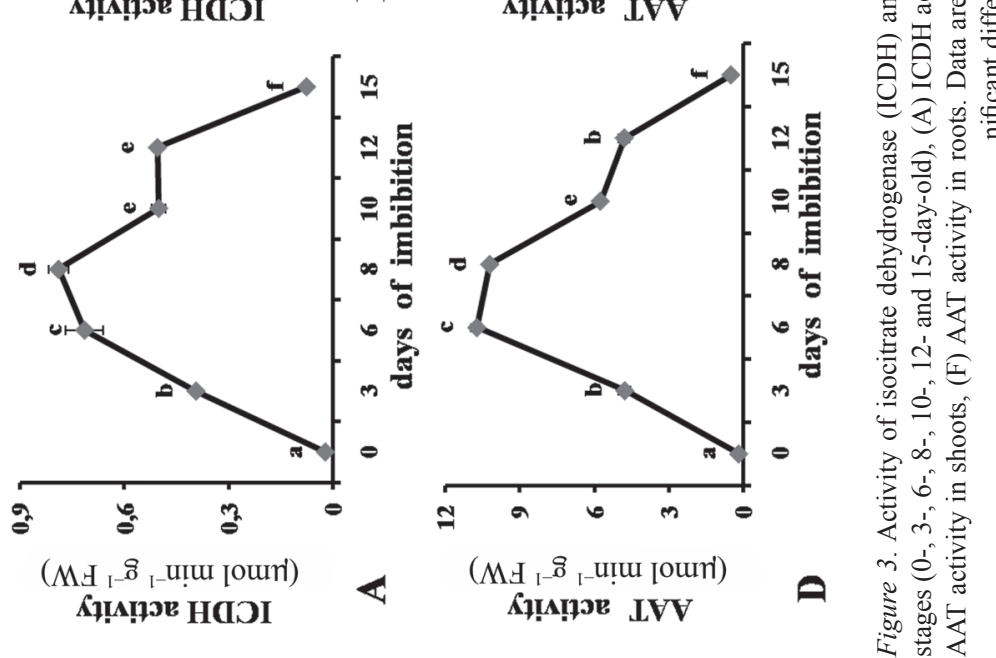

Cereal Research Communications 45, 2017 


\section{Discussion}

During germination, the growth of seedlings is dependent on the release of nutrients from the seed storage compounds. Thus, the high levels of GS activity in the germinating seed could lead to faster germination by amino acid biosynthesis (Sreenivasulu et al. 2008) or hormonal control, particularly by gibberellic acid, is part of the regulation of cytosolic GS in the early stages of pine development (Gómez-Maldonado et al. 2004). Ávila et al. (2001) have observed an abundance of GS1b polypeptides and transcripts in the embryo of pine suggesting that the function of GS1b during the initial stages of germination may be important for de novo protein biosynthesis possibly related with the loss of seed dormancy (Schneider and Gifford 1994). These authors have also proposed that GS1b is the functional gene in the reassimilation of ammonium released in the breakdown of embryo storage proteins at early stages of germination. In our study, the GS activity in the shoots was higher as compared to the seeds and the roots, which indicate that the major part of the degraded protein storage is transported to shoots, where de novo amino acids are synthesized. These results are in agreement with those obtained by Ávila et al. (2001) who found that in pine a GS1a polypeptide was most exclusively expressed in photosynthetic tissues of the seedling generating amino donors for the biosynthesis of major nitrogenous compounds in photosynthetic tissues.

In this study, we have found an increase in the seeds aminating GDH activity occurred mainly during the early stages of the post-germinative phase, which may suggest that this enzyme coordinate with GS at these stages, and participates also in the assimilation of ammonia derived from storage protein degradation. Grabowska et al. (2011) have reported that the aminating activity of GDH was lower compared to the deaminating activity at the early stages of the seed germination. However, after $48 \mathrm{~h}$ of germination, a significant increase in the aminating activity was observed and exceeded 1.3 times the GDH activity in the deaminating direction. For these authors, the GDH activity decreased in shoots and roots from 48 to $72 \mathrm{~h}$ and they also observed that roots have significantly higher activity compared to shoots. Here, we showed that the aminating activity of GDH decreased in roots and shoots starting from the $3^{\text {rd }}$ DAI. It was reported that the ratio of aminating to deaminating GDH activity varied depending on the organ and the physiological status of a given organ (Ferrario-Méry et al. 2002). This variation may be an adaptive mechanism to the carbon skeletons requirement (Lea and Ireland 1999).

PEPC has been suggested to fulfil a crucial function very early in the germination process to build up cellular pools of $\mathrm{C}_{4}$ acids needed to trigger subsequent TCA (Sangwan et al. 1992). Which allows the synthesis of 2-oxoglutarate for the GS/GOGAT cycle. This explains the increase of PEPC activity observed in our study. González et al. (1998) reported that following imbibition, the enzyme is abundant in most tissues of the grain. This activity may generate carbon skeletons to help supply the demand of amino acid biosynthesis. Other role of PEPC can play in germinating seed is deeply committed to the synthesis and secretion of hydrolytic enzymes and the transport of nutrients (such as sugars and amino acids) from the starchy endosperm (Drozdowicz and Jones 1995). Our results showed that PEPC activity was higher in the shoots as compared to the roots and the 
seeds. This explains the result obtained for the GS activity. Therefore, the high activity of PEPC in the shoots could be essential for the supply of carbon compounds required for the synthesis of amino acids and thus, proteins.

It was reported that among the TCA cycle enzymes, MDH is highly increased in activity during early germination (Soeda et al. 2005). Cytosolic NAD ${ }^{+}-\mathrm{MDH}$ catalyzes the formation of malate from OAA generated by PEPC. This malate enters in mitochondria where mitochondrial MDH catalyzes conversion of malate to OAA (Gietl 1992). The OAA formed is then used in the TCA cycle. In this way, the increase of PEPC and NAD ${ }^{+}$ $\mathrm{MDH}$ in developing seeds appears to be essential for growth processes as they allow TCA cycle to continue. Proteomic analysis has revealed that MMDH1 was one of 95 proteins that significantly accumulate during Arabidopsis seed germination (Fu et al. 2005). Also, a comprehensive Arabidopsis seed transcriptome analysis documented that the transcript abundance of MMDH1 and MMDH2 was significantly up-regulated at the earliest stages of seed germination (Weitbrecht et al. 2011).

In the literature, ICDH and AAT are the two main candidates of the key organic acid for plant ammonium assimilation (Hodges et al. 2003). In this study, the ICDH activity in seeds increased from 0 (dry seeds) to the $8^{\text {th }}$ DAI. These results are in agreement with those obtained by Pascual et al. (2008) who found that expression of cytosolic NADP ${ }^{+}$ IDH transcripts and polypeptides increased following germination of pine embryos, suggesting a role of the enzyme during active cell proliferation and development of seedling organs and structures. The same authors have observed an up-regulation of NADP ${ }^{+}$-IDH during germination in the parenchyma of embryonic cotyledons and the strong RNA and polypeptide signals in cotyledons of seedlings may be associated with the synthesis of nitrogen compounds required for acquisition of photosynthetic competence. In roots and shoots, this activity decreased continuously from the $3^{\text {rd }}$ to the $15^{\text {th }}$ DAI. Airaki et al. (2015) have observed that the ICDH enzyme in roots and hypocotyls of pepper significantly decreased from day 7 to day 14 .

The seeds AAT activity, increased from 0 to the $6^{\text {th }}$ DAI. Isola and Franzoni $(2000)$ reported that AAT activity of peanut cotyledons increases throughout seed germination achieving its maximum value about the 6th DAI and then remained constant. The increase AAT activity at this stage is consistent with its role in the conversion of glutamate, produced during ammonium assimilation, to aspartate. De la Torre et al. (2006) have previously reported the coordinated expression of AAT type prokaryotic and GS upon germination of seed and during pine seedling development. These authors proposed that this form of AAT could be involved in biosynthesis of the aspartate-derived amino acids lysine, threonine and isoleucine, as well as precursors of methionine biosynthesis (Coruzzi and Last 2000).

The carbon and nitrogen pathways are highly interconnected, where reductants and energy produced from carbohydrate metabolism are used by nitrogen assimilatory enzymes to perform nitrogen assimilation in plants. In this study, we have observed that during germination and seedlings development the most activities of nitrogen and carbon metabolism enzymes (GS, GDH, PEPC, MDH, ICDH and AAT) were correlated (nearly show similar kinetic changes) and influenced by their cellular environment and develop- 
mental stage. Therefore, higher activities of these enzymes were observed in the seed, root and shoot at early stages of the post-germinative phase could be effectively linked to the demand of de novo proteins to ensure a good development of seedlings.

\section{References}

Airaki, M., Leterrier, M., Valderrama, R., Chaki, M., Begara-Morales, J.C., Barroso, J.B., del Rio, L.A., Palma, J.M., Corpas, F.J. 2015. Spatial and temporal regulation of the metabolism of reactive oxygen and nitrogen species during the early development of pepper (Capsicum annuum) seedlings. Ann. Bot. 116:679-693.

Ávila, C., Cantón, F.R., Barnestein, P., Suárez, M.F., Marraccini, P., Rey, M., Humara, J.M., Ordas, R., Cánovas, F.M. 2001. The promoter of a cytosolic glutamine synthetase gene from the conifer Pinus sylvestris is active in cotyledons of germinating seeds and light-regulated in transgenic Arabidopsis thaliana. Physiologia Plant. 112:388-396.

Bakrim, N., Prioul, J.L., Dellens, E., Rocher, J.P., Arrio-Dupont, M., Vidal, J., Gadal, P., Chollet, R. 1993. Regulatory phosphorylation of $\mathrm{C} 4$ phosphoenolpyruvate carboxylase: a cardinal event influencing the photosynthesis rate in Sorghum and maize. Plant Physiol. 10:891-897.

Bradford, M.M. 1976. A rapid and sensitive method for the quantification of microgram quantities of protein utilizing the principle of protein-dye binding. Anal. Biochem. 72:248-254.

Buchanan, B.B., Gruissem, W., Jones, R.L. 2000. Biochemistry and Molecular Biology of Plants. Am. Soc. of Plant Physiologists. Rockville, MD, USA. pp. 549-556.

Chen, R.D., Gadal, P. 1990. Do mitochondria provide the 2-oxoglutarate needed for glutamate synthesis in higher plant chloroplasts? Plant Physiol. and Biochem. 28:141-145.

Coruzzi, G., Last, R. 2000. Amino acids. In: Buchanan, B. B., Gruissem, W., Jones, R. (eds), Biochemistry and Molecular Biology of Plants. Am. Soc. of Plant Physiologists. Rockville, MD, USA. pp. 358-410.

De la Torre, F., de Santis, L., Suárez, M.F., Crespillo, C., Cánovas, F.M. 2006. Identification and functional analysis of a prokaryotic-type aspartate aminotransferase: implications for plant amino acid metabolism. Plant J. 46:414-425.

Drozdowicz, Y.M, Jones, R.L. 1995. Hormonal regulation of organic and phosphoric acid release by barley aleurone layers and scutella. Plant Physiol. 108:769-776.

El Omari, R., Rueda-López, M., Avila, C., Crespillo, R., Nhiri, M., Cánovas, F.M. 2010. Ammonium tolerance and the regulation of two cytosolic glutamine synthetases in the roots of sorghum. Functional Plant Biol. 37:55-63.

Ferrario-Méry, S., Valadier, M.H., Godefroy, N., Miallier, D., Hirel, B., Foyer, C.H., Suzuki, A. 2002. Diurnal changes in ammonia assimilation in transformed tobacco plants expressing ferredoxin-dependent glutamate synthase mRNA in the antisense orientation. Plant Sci. 163:59-67.

Fu, Q., Wang, B.C., Jin, X., Li, H.B., Han, P., Wei, K.H., Zhang, X.M., Zhu, Y.X. 2005. Proteomic analysis and extensive protein identification from dry, germinating Arabidopsis seeds and young seedlings. J. of Biochem. and Mol. Biol. 38:650-660.

Gietl, C. 1992. Malate dehydrogenase isoenzymes: cellular locations and role in the flow of metabolites between the cytoplasm and cell organelles. Biochimica et Biophysica Acta (BBA). Bioenergetics 1100:217234.

Gómez-Maldonado, J., Ávila, C., de la Torre, F., Canas, R., Cánovas, F.M., Campbell, M.M. 2004. Functional interactions between a glutamine synthetase promoter and MYB proteins. Plant J. 39:513-526.

González, M.C., Osuna, L., Echevarría, C., Vidal, J., Cejudo, F.J. 1998. Expression and localization of phosphoenolpyruvate carboxylase in developing and germinating wheat grains. Plant Physiol. 116:1249-1258.

Grabowska, A., Nowicki, M., Kwinta, J. 2011. Glutamate dehydrogenase of the germinating triticale seeds: gene expression, activity distribution and kinetic characteristics. Acta Physiologiae Plant. 33:1981-1990.

Guan, M., Møller, I.S., Schjørring, J.K. 2015. Two cytosolic glutamine synthetase isoforms play specific roles for seed germination and seed yield structure in Arabidopsis. J. Exp. Bot. 66:203-212.

Hodges, M., Flesch, V., Gálvez, S., Bismuth, E. 2003. Higher plant NADP ${ }^{+}$-dependent isocitrate dehydrogenases, ammonium assimilation and NADPH production. Plant Physiol. and Biochem. 41:577-585. 
Isola, M.C., Franzoni, L. 2000. Changes of aspartate aminotransferase activity, its isoform pattern, and free amino acids content in peanut cotyledons during seed germination. Acta Physiologiae Plant. 22:125-128.

Izui, K., Matsumura, H., Furumoto, T., Kai, Y. 2004. Phosphoenolpyruvate carboxylase: a new era of structural biology. Annu. Rev. Plant Biol. 55:69-84.

Lea, P.J., Ireland, R.J. 1999. Nitrogen metabolism in higher plants. In: Singh, B.K. (ed.), Plant Amino Acids: Biochemistry and Biotechnology. Marcel Dekker, Inc. New York-Basel. pp. 1-47.

Magalhaes, J.R., Huber, D.M. 1991. Response of ammonium assimilating enzymes to nitrogen form treatments in different plant species. J. Plant Nutr. 14:175-185.

Nhiri, M., Bakrim, N., Pacquit, V., Elhachimi-Messouak, Z., Osuna, L., Vidal, J. 1998. Calcium-dependent and -independent phosphoenolpyruvate carboxylase kinase in sorghum leaves: further evidence for the involvement of the calcium-independent protein kinase in the in situ regulatory phosphorylation of $\mathrm{C} 4$ phosphoenolpyruvate carboxylase. Plant Cell Physiol. 39:241-246.

Oaks, A. 1997. Strategies of nitrogen assimilation in Zea mays: early seedling growth. Maydica 42:203-210.

Osuna, D., Prieto, P., Aguilar, M. 2015. Control of seed germination and plant development by carbon and nitrogen availability. Frontiers in Plant Sci. 6:1023.

Pascual, B.M., Molina-rueda, J.J., Cánovas, F.M., Gallardo, F. 2008. Spatial distribution of cytosolic NADP ${ }^{+}$ isocitrate dehydrogenase in pine embryos and seedlings. Tree Physiol. 28:1773-1782.

Rej, R. 1979. Measurement of aspartate aminotransferase activity: effects of oxamate. Clinical Chem. 25:555559.

Sangwan, R.S., Singh, N., Plaxton, W.C. 1992. Phosphoenolpyruvate carboxylase activity and concentration in the endosperm of developing and germinating castor oil seeds. Plant Physiol. 99:445-449

Sarasketa, A., González-Moro, M.B., González-Murua, C., Marino, D. 2014. Exploring ammonium tolerance in a large panel of Arabidopsis thaliana natural accessions. J. Exp. Bot. 65:6023-6033.

Schneider, W.I., Gifford, D.J. 1994. Loblolly pine seed dormancy. I. The relationship between protein synthesis and the loss of dormancy. Physiologia Plant. 90:246-252.

Setién, I., Fuertes-Mendizabal, T., González, A., Aparicio-Tejo, P.M., González-Murua, C., González-Moro, M.B., Estavillo, J.M. 2013. High irradiance improves ammonium tolerance in wheat plants by increasing N assimilation. J. Plant Physiol. 170:758-771.

Setién, I., Vega-Mas, I., Celestino, N., Calleja-Cervantes, M.E., González-Murua, C., Estavillo, J.M., González-Moro, M.B. 2014. Root phosphoenolpyruvate carboxylase and NAD-malic enzymes activity increase the ammonium-assimilating capacity in tomato. J. Plant Physiol. 171:49-63.

Shapiro, B.M., Stadtman, E.R. 1970. Glutamine synthetase (Escherichia coli). In: Tabor, H., Tabor, W.C. (eds), Methods in Enzymology. Academic Press. New York and London. 17A: pp. 910-912.

Soeda, Y., Konings, M.C., Vorst, O., Van Houwelingen, A.M., Stoopen, G.M., Maliepaard, C.A., Kodde, J., Bino, R.J., Groot, S.P.C., Van der Geest, A.H.M. 2005. Gene expression programs during Brassica oleracea seed maturation, osmopriming, and germination are indicators of progression of the germination process and the stress tolerance level. Plant Physiol. 137:354-368.

Sreenivasulu, N., Usadel, B., Winter, A., Radchuk, V., Scholz, U., Stein, N., Weschke, W., Strickert, M., Close, T.J., Stitt, M., Graner, A., Wobus, U. 2008. Barley grain maturation and germination: metabolic pathway and regulatory network commonalities and differences highlighted by new MapMan/PageMan profiling tools. Plant Physiol. 146:1738-1758.

Valadier, M.H., Yoshida, A., Grandjean, O., Morin, H., Kronenberger, J., Boutet, S., Raballand, A., Hase, T., Yoneyama, T., Suzuki, A. 2008. Implication of the glutamine synthetase/glutamate synthase pathway in conditioning the amino acid metabolism in bundle sheath and mesophyll cells of maize leaves. F.E.B.S. Journal 275:3193-3206.

Weitbrecht, K., Müller, K., Leubner-Metzger, G. 2011. First off the mark: early seed germination. J. Exp. Bot. 62:3289-3309. 